\title{
Simultaneous determination of absorption of selenium from poultry meat and selenite in young men: application of a triple stable-isotope method
}

\author{
BY MERRILL J. CHRISTENSEN*\|, MORTEZA JANGHORBANI*†§, \\ FRED H. STEINKE + NAWFAL ISTFAN* AND VERNON R. YOUNG* \\ *Department of Nutrition and Food Science, and $\dagger$ Nuclear Reactor Laboratory, \\ Massachusetts Institute of Technology, 138 Albany Street, Cambridge, \\ Massachusetts 02139, USA and $\ddagger$ Central Research, Ralston Purina Company, St Louis, \\ Missouri 63188, USA
}

(Received 9 July 1982 - Accepted 18 February 1983)

1. A triple stable-isotope method was used to estimate simultaneously selenium absorption from poultry meat intrinsically labelled with ${ }^{74} \mathrm{Se}$ and from an extrinsic tracer of ${ }^{76} \mathrm{SeO}_{3}{ }^{2-}$ in four young adult men. The subjects received an experimental diet based on chicken meat as the source of protein. Two diet periods, lasting from 5 to $10 \mathrm{~d}$, depending on the frequency of stool output for each subject, were conducted to allow duplicate determinations within each subject of Se absorption from both sources.

2. Absorption of Se was determined by the faecal isotope balance procedure through monitoring the stable isotopes ${ }^{74} \mathrm{Se},{ }^{76} \mathrm{Se}$ and ${ }^{80} \mathrm{Se}$ by means of radiochemical neutron activation analysis.

3. For the separate periods, mean (with SEM) absorption of ${ }^{74} \mathrm{Se}$ from the intrinsically-labelled poultry meat was $70.9(1.5) \%$ and $72.0(2 \cdot 5) \%$. The absorption of Se from ${ }^{76} \mathrm{SeO}_{3}{ }^{2-}$ was $34.7(5.5) \%$ and $37.6(3.2) \%$ during the same periods.

4. From these results it is concluded that, under the present experimental conditions, the intrinsic and extrinsic Se isotopes did not form a common pool before absorption. Possible reasons for this are discussed.

Previous measurements of dietary selenium absorption in man have required the use of the radioisotope ${ }^{75}$ Se (Thomson \& Stewart, 1974; Griffiths et al. 1976; Heinrich et al. 1977). Recently, we have explored the feasibility of applying a stable-isotope method to determine absorption and other indices of Se metabolism in human subjects (Janghorbani et al. 1982a). In this earlier study young men received, after an overnight fast, an oral dose of a solution of selenite highly-enriched with the stable isotope ${ }^{74} \mathrm{Se}$. However, in order to determine whether a tracer dose of ${ }^{74} \mathrm{SeO}_{3}{ }^{2-}$ could be used to estimate the absorption of Se from meals of test foods, it is necessary to assess the extent to which this tracer exchanges with the entire pool of dietary Se before its absorption.

The problem of isotope exchangeability has been explored in studies of non-haeme iron (Björn-Rasmussen et al. 1974; Layrisse et al. 1975; Cook, 1977; Hallberg, 1981) and zinc (Evans \& Johnson, 1977; Sandström \& Cedarblad, 1980; Janghorbani et al. 1982b) absorption. However, there are no published reports concerned with an exploration of this problem in reference to the determination of Se absorption. Furthermore, it cannot easily be predicted from the available literature whether labelled selenite, when given as an extrinsic label together with Se-containing foods, would serve as a reliable index of the absorption of Se from these foods.

In the present study we have investigated these problems by exploiting a procedure, described previously (Janghorbani et al. 1981 a), for intrinsic labelling of chicken meat with the stable isotope ${ }^{74} \mathrm{Se}$. Young men were given a meal of chicken intrinsically-labelled with

|| Present address: Department of Food Science and Nutrition, Brigham Young University, Provo, Utah 84602, USA.

$\S$ For reprints. 
${ }^{74} \mathrm{Se}$ together with a solution of sodium selenite enriched with another stable isotope, ${ }^{76} \mathrm{Se}$. Absorption of the two isotopes was then determined with the aid of a triple-isotope method that we have developed for this purpose.

\section{MATERIALS AND METHODS}

Subjects. Four healthy, young, adult male students from the Massachusetts Institute of Technology (MIT) were selected for participation in the study on the basis of medical history, thorough physical examination and biochemical screening tests on blood and urine. The study protocol was approved by the MIT Committee on the Use of Humans as Experimental Subjects and by the Executive and Policy Committees of the MIT Clinical Research Center. Each subject was fully informed of the purpose, nature and design of the experiment. The subjects were required to sign written consent forms and they were paid for their participation in the study. At 08.00 hours daily throughout the entire study each subject was weighed under standardized conditions (preprandial, post-voiding and with light clothing). They engaged in their usual daily activities and were asked to maintain a reasonably constant level of physical activity. A diary of significant events was kept by each subject and was checked periodically by one of the investigators.

Diets. Chicken meat was served as the only source of protein throughout the study. The chicken meat had previously been boiled, deboned, ground and formed into patties. Each subject received $454 \mathrm{~g}$ daily of ground chicken meat. The patties were warmed in a microwave oven before consumption. Additional energy was provided by protein-free cookies, pudding and sweetened beverages. Vitamin and mineral capsules were given to meet or exceed requirements for micronutrients (Table 1). The daily intake was divided into three isonitrogenous, iso-energetic meals.

On the days of isotope administration, chicken meat intrinsically labelled with ${ }^{74} \mathrm{Se}$ was substituted for the unlabelled meat. On these test days each subject received $340.5 \mathrm{~g}$ isotopically-labelled chicken meat that had previously been boiled but was consumed without previous heating. $1 \mathrm{ml}$ of a solution containing $21.8 \mu \mathrm{g}{ }^{76} \mathrm{Se}\left(\right.$ as $\left.{ }^{76} \mathrm{SeO}_{3}{ }^{2-}\right) / \mathrm{ml}$ was pipetted on to each intrinsically-labelled pattie and carefully kneaded into the pattie, as described later. Thus, on the isotope days each subject received $65.4 \mu \mathrm{g}{ }^{76} \mathrm{Se}$ as an extrinsic label (Table 2). The mineral supplement given on these days was essentially devoid of Se.

Labelling and preparation of poultry meat. We have described in detail elsewhere the procedure for the intrinsic labelling of chicken meat with ${ }^{74} \mathrm{Se}$ (Janghorbani et al. 1981a). However, in brief, the procedure is as follows: 1-d-old cockerel, broiler-type chickens were obtained from a commercial hatchery. Feed and water were supplied ad lib. to the chicks for the next 6 weeks. During this time the birds were periodically intubated with ${ }^{74} \mathrm{SeO}_{3}{ }^{2-}$. After $42 \mathrm{~d}$ the chickens were killed, bled, defeathered, eviscerated and frozen at $-40^{\circ}$. They were then shipped frozen to MIT after packing in Cryovac bags (Cryovac Div., W. R. Grace \& Co., Duncan, SC, USA).

To prepare the meat for consumption the chickens were thawed, boiled and deboned. The meat and skin from all labelled chickens were passed through a meat grinder and further mixed by hand. The mixture was then frozen until used in the experiment. On the day before serving, an appropriate quantity of the labelled meat mixture was thawed and formed into patties. The Se isotopic content of the intrinsically-labelled chicken-meat patties is shown in Table 3.

Preparation and administration of the extrinsic label. Elemental ${ }^{76} \mathrm{Se}$ (Oak Ridge National Laboratories, Tennessee; isotope $96.8 \%$ ) weighing $2.25 \mathrm{mg}$ was dissolved in a few drops of concentrated nitric acid. The solution was diluted to $100 \mathrm{ml}$ with deionized water to give a final concentration of $21.8 \mu \mathrm{g}{ }^{76} \mathrm{Se} / \mathrm{ml}$. 
Table 1. Composition of diets fed to subjects during the simultaneous absorption study

\begin{tabular}{lcc}
\hline \hline \multicolumn{1}{c|}{ Ingredient } & $\begin{array}{c}\text { Amount } \\
(\mathrm{g} / \mathrm{d})\end{array}$ \\
\hline $\begin{array}{l}\text { Chicken meat pattie } \\
\text { Non-protein energy sourcest: } \\
\text { Protein-free cookies }\end{array}$ & $454(340 \cdot 5)^{*}$ \\
& Maize-starch dessert & Variable \\
Sweetened beverages & Variable \\
Vitamin and mineral supplements $\ddagger$ & Variable \\
Water & Variable \\
& ad lib. \\
\hline
\end{tabular}

* Quantity given on days of isotope administration.

$\uparrow$ Variable among subjects but constant for each individual. Composition of sources described by Young $\mathrm{et} \mathrm{al}$. (1971).

$\ddagger$ Included: (1) One-a-day multivitamin-multimineral capsule (Miles Laboratories, Inc., Elkhart, IN 46515) containing $1000 \mu \mathrm{g}$ retinol, $15 \mathrm{mg} \mathrm{DL}-\alpha$-tocopherol acetate, ascorbic acid $60 \mathrm{mg}$, folic acid $0.4 \mathrm{mg}$, thiamine $1.5 \mathrm{mg}$, riboflavin $1.7 \mathrm{mg}$, niacin $20 \mathrm{mg}$, pyridoxine $2 \mathrm{mg}$, vitamin $\mathrm{B}_{12} 6 \mu \mathrm{g}$, vitamin $\mathrm{D}_{3} 10 \mu \mathrm{g}$, pantothenic acid $10 \mathrm{mg}$, iron (elemental) $18 \mathrm{mg}$, calcium $100 \mathrm{mg}$, phosphorus $100 \mathrm{mg}$, iodine $150 \mu \mathrm{g}$, magnesium $100 \mathrm{mg}$, copper $2 \mathrm{mg}$, zinc $19 \mathrm{mg}$; (2) two choline tablets (250 mg each; Choline Bitartrate Plus Products, Irvine, CA 92705); (3) trace mineral capsule containing $400 \mathrm{mg} \mathrm{Mg}$ as $\mathrm{MgO}, 2 \mathrm{mg} \mathrm{Cu}$ as $\mathrm{CuCl}_{2} .2 \mathrm{H}_{2} \mathrm{O}, 1.7 \mathrm{mg}$ manganese as $\mathrm{MnSO}_{4} \cdot \mathrm{H}_{2} \mathrm{O}$, $80 \mu \mathrm{g}$ molybdenum as $\mathrm{Na}_{2} \mathrm{MoO}_{4} \cdot 2 \mathrm{H}_{2} \mathrm{O}, 170 \mu \mathrm{g}$ chromium as $\mathrm{Cr}_{2}\left(\mathrm{SO}_{4}\right)_{3} .15 \mathrm{H}_{2} \mathrm{O}, 114 \mu \mathrm{g}$ selenium as $\mathrm{Na}_{2} \mathrm{SeO}_{3}$, $2 \mathrm{mg}$ aluminium as $\mathrm{AlK}\left(\mathrm{SO}_{4}\right)_{2} . \mathrm{H}_{2} \mathrm{O}, 290 \mu \mathrm{g} \mathrm{I}$ as $\mathrm{KI}$. The trace mineral capsule given on days of isotope administration contained $4 \mu \mathrm{g}$ Se (as $\mathrm{Na}_{2} \mathrm{SeO}_{3}$ ), otherwise composition identical to former; (4) sodium chloride tablets (Eli Lilly and Co., Indianapolis, IN; Enseals no. 27, 1 g U.S.P. (Enteric)).

Table 2. Daily intake of protein, energy and selenium for young men during the simultaneous stable-isotope absorption study

(Mean values for four subjects)

\begin{tabular}{|c|c|c|}
\hline Dietary constituent & Basal & Labelled diet \\
\hline Protein $(\mathrm{g})$ & 143.5 & 107.6 \\
\hline Energy $(\mathrm{kJ})$ & 13966 (SE 335) & 13221 (SE 335) \\
\hline \multicolumn{3}{|l|}{ Selenium $(\mu \mathrm{g})$ from: } \\
\hline Chicken & 107 & 85 \\
\hline $\begin{array}{l}\text { Mineral supplement or } \\
\text { extrinsic label } \mathrm{SeO}_{3}^{2-}\end{array}$ & 114 & 69 \\
\hline Total ${ }^{74} \mathrm{Se}$ & 0.87 & $13 \cdot 5$ \\
\hline Total ${ }^{76} \mathrm{Se}$ & $9 \cdot 3$ & 71.6 \\
\hline
\end{tabular}

Table 3. Isotopic analysis of ${ }^{24}$ Se-enriched chicken meat patties used in the study of selenium absorption

(Mean values with their standard errors for nine samples)

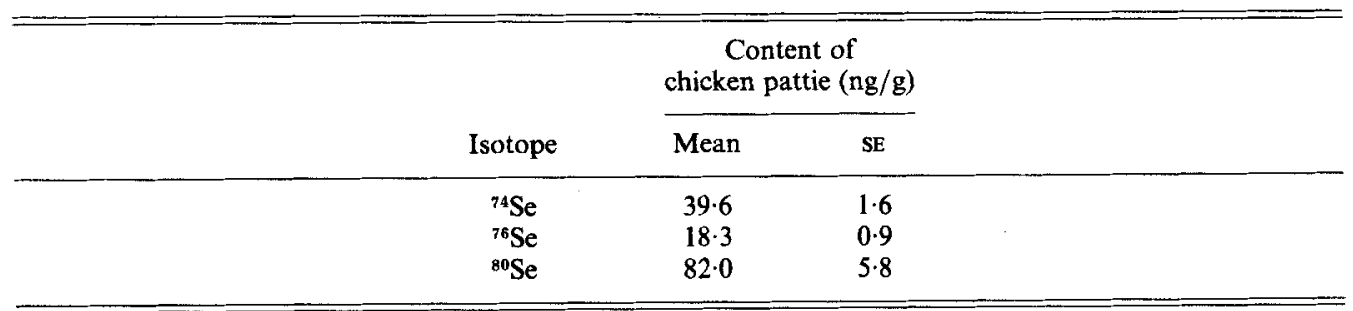


Table 4. Definition of terms used in eqns 1,2 and 3 for determination of absorption of extrinsic and intrinsic food labels of selenium

\begin{tabular}{ll}
\hline \hline Term & Definition \\
\hline$A_{f, 74}$ & Total ${ }^{74} \mathrm{Se}$ in faeces \\
$A_{f, 76}$ & Total ${ }^{76} \mathrm{Se}$ in faeces \\
$A_{f, 80}$ & Total ${ }^{80} \mathrm{Se}$ in faeces \\
$F_{1}$ & Fractional absorption of Se from the intrinsically-labelled chicken meat \\
$A_{0,74,1}^{*}$ & Quantity of dietary ${ }^{74} \mathrm{Se}$ from the labelled chicken meat (the intrinsic label) \\
$A_{0,76,1}$ & Quantity of dietary ${ }^{76} \mathrm{Se}$ from the labelled chicken meat \\
$A_{0,80,1}$ & Quantity of dietary ${ }^{80} \mathrm{Se}$ from the labelled chicken meat \\
$F_{2}$ & Fractional absorption of Se from the selenite solution used as the extrinsic label \\
$A_{0,74,2}$ & Quantity of dietary ${ }^{74} \mathrm{Se}$ from selenite solution \\
$A_{0,76,2}^{*}$ & Quantity of dietary ${ }^{76} \mathrm{Se}$ from selenite solution (the extrinsic label) \\
$A_{\mathbf{0}, 80,2}$ & Quantity of dietary ${ }^{80} \mathrm{Se}$ from selenite solution \\
$A_{n, 80}$ & Quantity of ${ }^{80} \mathrm{Se} \mathrm{in} \mathrm{faeces} \mathrm{from} \mathrm{all} \mathrm{natural,} \mathrm{unenriched} \mathrm{sources}$ \\
$R_{74 / 80}$ & Natural ratio, ${ }^{74} \mathrm{Se:}{ }^{80} \mathrm{Se}$ \\
$R_{76 / 80}$ & Natural ratio, ${ }^{78} \mathrm{Se}:{ }^{80} \mathrm{Se}$ \\
\hline \hline
\end{tabular}

On the day before the isotope study, $1 \mathrm{ml}$ of this solution was pipetted into a depression in the ${ }^{74} \mathrm{Se}$-labelled chicken patties for serving to the subjects during each of three meals on the following day. The solution was carefully kneaded into the patties by hand and the patties then kept at $4^{\circ}$ overnight in the refrigerator.

Experimental design. For the first $3 \mathrm{~d}$ all subjects consumed the unlabelled, basal diet (Table 2). On day 4 they were given the intrinsically-labelled chicken meat containing the extrinsic label of ${ }^{76} \mathrm{SeO}_{3}{ }^{2-}$. On the following day the subjects were again given the basal diet and they continued with this diet until each had passed stools on five different days following isotope administration. On the day after this 5th day of post-isotope stool collection, each subject was given the basal diet and the procedure for the collection of stools repeated as in the first isotope period. Thus, the two dietary periods were essentially identical, allowing an estimate of the reproducibility of the determination of Se absorption from both sources.

All stools were collected quantitatively during the entire study. A preliminary analysis of individual stool collections was carried out to determine which stools contained the unabsorbed tracer. These stools were then pooled for each subject and period and each pool was analysed in triplicate for ${ }^{74} \mathrm{Se},{ }^{76} \mathrm{Se}$ and ${ }^{80} \mathrm{Se}$ by the method of radiochemical neutron activation analysis, as described previously (Janghorbani et al. 1981c).

\section{RESULTS AND DISCUSSION}

Principles of the method. The principles and procedures for the measurement of absorption using the stable-isotope balance method and a single isotope tracer have been discussed previously (Janghorbani et al. 1980). In the present experiment, employing simultaneously two isotope labels, fractional absorption of both the extrinsic and intrinsic labels may be calculated by solving the following three equations:

$$
\begin{aligned}
& A_{f, 74}=A_{0,74,1}^{*}\left(1-F_{1}\right)+A_{0,74,2}\left(1-F_{2}\right)+R_{74 / 80} \times A_{n, 80} \\
& A_{f, 76}=A_{0,76,1}\left(1-F_{1}\right)+A_{0,76,2}^{*}\left(1-F_{2}\right)+R_{76 / 80} \times A_{n, 80} \\
& A_{f, 80}=A_{0,80,1}\left(1-F_{1}\right)+A_{0,80,2}\left(1-F_{2}\right)+A_{n, 80}
\end{aligned}
$$

where the definitions of the above terms are given in Table 4. Thus, the quantity of each isotope in faeces is the sum of the contributions from three sources: $(a)$ the chicken meat 
Table 5. Selenium absorption (\% ingested dose) from ${ }^{74} \mathrm{Se}$-labelled chicken and ${ }^{76} \mathrm{SeO}_{3}{ }^{2-}$, in young men

\begin{tabular}{|c|c|c|c|c|}
\hline \multirow[b]{2}{*}{ Subject } & \multicolumn{2}{|c|}{ Diet period 1} & \multicolumn{2}{|c|}{ Diet period 2} \\
\hline & Chicken- ${ }^{74} \mathrm{Se}$ & ${ }^{76} \mathrm{SeO}_{3}{ }^{2-}$ & Chicken $-{ }^{74} \mathrm{Se}$ & ${ }^{76} \mathrm{SeO}_{3}{ }^{2-}$ \\
\hline $\mathrm{RC}$ & $71 \cdot 0$ & $27 \cdot 3$ & 64.8 & $37 \cdot 1$ \\
\hline MD & $66 \cdot 9$ & $23 \cdot 5$ & $75 \cdot 4$ & $43 \cdot 2$ \\
\hline CG & $72 \cdot 0$ & $46 \cdot 3$ & $74 \cdot 5$ & $41 \cdot 4$ \\
\hline JD & $73 \cdot 6$ & $41 \cdot 4$ & 73.4 & $28 \cdot 8$ \\
\hline Mean (SEM) & $70.9(1.5)$ & $34 \cdot 7(5 \cdot 5)$ & $72 \cdot 0(2 \cdot 5)$ & $37 \cdot 6(3 \cdot 2)$ \\
\hline
\end{tabular}

enriched with ${ }^{74} \mathrm{Se} ;(b)$ the solution of enriched ${ }^{76} \mathrm{Se}$ given as an extrinsic label; and $(c)$ all other unenriched dietary and endogenous sources of Se in which the relative amounts of the three isotopes $\left({ }^{74} \mathrm{Se},{ }^{76} \mathrm{Se},{ }^{80} \mathrm{Se}\right)$ are those occurring in nature.

The parameters $A_{f, 74}, A_{f, 76}$, and $A_{f, 80}$ are measured quantities of the stable isotopes ${ }^{74} \mathrm{Se}$, ${ }^{76} \mathrm{Se}$ and ${ }^{80} \mathrm{Se}$ in the faecal pool prepared so as to contain all the unabsorbed labels (usually five consecutive stools post-ingestion); the six parameters designed $A_{0, i, j}$ are the measured isotopic contents of each labelled diet. Thus the three unknown quantities, $F_{1}, F_{2}$, and $A_{n, 80}$, can be calculated.

Of importance for precise determination of fractional absorption of Se is the number of stools, passed following isotopic administration, that are used to prepare a composite faecal pool before neutron activation analysis. If too few stools are included then all the unabsorbed isotope will not be determined and the calculated absorption value would be erroneously high. We have explored this issue in the cases of $\mathrm{Fe}$ (Janghorbani et al. 1980), Zn (Solomons et al. 1982), Ca (Janghorbani et al. 1981 b) and Se (M. J. Christensen, M. Janghorbani, F. H. Steinke and V. R. Young, unpublished results) and have determined that in the five consecutive stools following isotope ingestion virtually all unabsorbed tracer is present.

Errors would also be introduced if the period of faecal collection was too prolonged. In this case the faecal pool would include isotope that may have been absorbed but later resecreted into the gut. Thus, absorption values would be artificially low. In the case of $\mathrm{Ca}$ and $\mathrm{Se}$, the re-entry of absorbed isotope into the intestinal tract may be significant. However, the method of Lutwak (1969), involving analysis of the cumulative excretion of isotope in faeces, may be used to correct for this return of absorbed label into the intestinal tract. We have compared the results obtained for absorption of Se calculated by both methods using ${ }^{74} \mathrm{SeO}_{3}{ }^{2-}$ as an extrinsic label in four young adult men (Janghorbani et al. $1982 a$ ). The calculated values for mean (with SE) absorption were $75.9(9.3) \%$ and 76.6 $(8.9) \%$ using the faecal pooling method and the method of Lutwak (1969) respectively.

Fractional absorption of the two forms of Se. Values for adsorption of Se from chicken and from the extrinsic label of selenite for all subjects during both experimental periods are given in Table 5. The two estimates for mean values for absorption of ${ }^{74} \mathrm{Se}$-labelled chicken compared closely but the replication of the estimate of ${ }^{76} \mathrm{Se}$ absorption was not as close. The value for absorption of ${ }^{74} \mathrm{Se}$ from chicken meat is in general agreement with previously-published estimates of food Se absorption (Heinrich et al. 1977; Robinson et al. 1978; Stewart et al. 1978). However, in only one previous study has absorption of Se from an intrinsically labelled food been measured directly. In that study pork, obtained from pigs that had been given an injection of $\left.{ }^{75} \mathrm{Se}\right]$ selenomethionine, was given to healthy adults and to children suffering from cystic fibrosis (Heinrich et al. 1977). Estimates for food Se 
absorption derived in other studies have been based on the assumption that a radioactive tracer given orally as an extrinsic label is partitioned between urinary excretion and body retention in the same proportion as is food Se (Stewart et al. 1978). The validity of the assumption might be questioned, based on the known differences in the metabolism and excretion of the various chemical forms of ingested Se in humans (Thomson \& Stewart, 1974; Griffiths et al. 1976). Further uncertainty arises due to the paucity of information on the chemical forms of Se in different foods.

The estimate of absorption of Se from the intrinsically-labelled meat reported here is comparable to that obtained in a previous study in which intrinsically-labelled chicken meat was given to young men receiving an amino acid diet supplying adequate or low sulphuramino acid intakes (M. J. Christensen, M. Janghorbani, F. H. Steinke and V. R. Young, unpublished results). In that study, mean (with SE) absorption of ${ }^{74} \mathrm{Se}-$ labelled chicken was $70.2(3.2) \%$ and $64.7(1.8) \%$ for subjects receiving the adequate and low S-amino acid intakes respectively.

Thomson \& Stewart (1974) measured selenite absorption in three New Zealand women using radioactive ${ }^{75} \mathrm{SeO}_{3}{ }^{2-}$. Values for their individual subjects were 44,64 and $70 \%$. In the present study, absorption for ${ }^{76} \mathrm{SeO}_{3}{ }^{2-}$ was somewhat lower than the New Zealand values and also lower than the estimates we have previously obtained in male MIT students receiving a dose of ${ }^{74} \mathrm{SeO}_{3}{ }^{2-}$ after an overnight fast and shortly before ingestion of food in the form of a liquid formula (Janghorbani et al. 1982a). In unpublished studies (M. J. Christensen, M. Janghorbani and V. R. Young) we have observed in subjects, who have been studied after an overnight fast, that the absorption of ${ }^{74} \mathrm{SeO}_{3}{ }^{2-}$ is highest when given in water $3 \mathrm{~h}$ before a meal and slightly lower when mixed with orange juice, again $3 \mathrm{~h}$ before a meal, or served with orange juice and a solid meal.

In the present experiment the ${ }^{76} \mathrm{SeO}_{3}{ }^{2-}$ solution was first mixed in with the chicken-meat patties and these were consumed together with additional protein-free cookies, pudding and sweetened beverages. It appears, therefore, that the way in which the extrinsic label is incorporated into a test meal or the physical form of the meal or both may affect the fractional absorption of $\mathrm{SeO}_{3}{ }^{2-}$.

Cousins \& Cairney (1961) and Butler \& Peterson (1962) have demonstrated in sheep that a reduction of Se to its elemental form by micro-organisms in the rumen may render it unavailable for absorption. Selenite is reduced in vitro to elemental Se by reducing agents such as ascorbic acid but, in chicks, ascorbic acid appears to enhance $\mathrm{SeO}_{3}{ }^{2-}$ absorption (Combs \& Pesti, 1976). We have demonstrated a similar although less marked effect of ascorbic acid on selenite-Se absorption in adult humans (M. J. Christensen, M. Janghorbani and V. R. Young, unpublished results). Nevertheless, the question arises as to whether a reducing agent present in the chicken meat might have caused the lower level of Se absorption from selenite added as a tag.

An alternative explanation for the low values for selenite absorption obtained in this study is that the extrinsic label of the ${ }^{76} \mathrm{SeO}_{3}{ }^{2-}$ reacted with a constituent of the chicken pattie leading to a reduction in its absorption. For example, selenite reacts readily with sulphydryl groups to form selenotrisulphides (Ganther, 1968). The latter are relatively unstable, decomposing to the disulphide and elemental Se (Ganther, 1968), with this being of low availability. Chicken skin, which accounted for approximately $200 \mathrm{~g} / \mathrm{kg}$ of the patties as served to our subjects, has a protein content of 120-140 g/ $\mathrm{kg}$ (Suderman \& Cunningham, 1980). Epidermal proteins are known to be rich in S-amino acids and also less soluble and thus possibly of lower digestibility than the intracellular proteins in the muscle cells (Rudall, 1952). The epidermal protein keratin is not digested by trypsin or pepsin and is only extensively soluble at high $\mathrm{pH}$ in agents such as sodium cyanide, sodium sulphide or sodium thioglycolate (Goddard \& Michaelis, 1934). 
We have reported a similar application of the double-labelling, triple stable-isotope method for study of isotopic exchangeability between $\mathrm{Zn}$ in poultry meat intrinsically-labelled with ${ }^{68} \mathrm{Zn}$ and an extrinsic label of ${ }^{70} \mathrm{ZnCl}_{2}$ (Janghorbani et al. 1982b). In the latter study we observed a small but statistically-significant difference between the fractional absorption of $\mathrm{Zn}$ from the extrinsic label and that from chicken meat, with absorption of the latter being slightly higher. However, the values for absorption for the two labels within subjects and between different diets were highly correlated $\left(r^{2} 0.93\right)$. In the present study there was no significant correlation $\left(r^{2} 0.21\right)$ between absorption of the extrinsic and intrinsic Se labels, due perhaps to the limited number of observations and the wide inter-individual variability in ${ }^{76} \mathrm{SeO}_{3}{ }^{2-}$ absorption.

In summary, the present study demonstrates the feasibility of undertaking simultaneous absorption determinations of stable isotopes of Se. The triple-isotope methodology described here is uniquely suited to the study of double-labelled diets since there is only one convenient radioactive isotope of Se for use in human metabolic studies. However, because the absorption of a dose of ${ }^{76} \mathrm{SeO}_{3}{ }^{2-}$ given simultaneoulsy as an extrinsic label was lower than previously-reported values for selenite absorption and less than that obtained for absorption of Se intrinsic to chicken meat, this suggests the need for caution in using labelled selenite as a means of estimating absorption of the Se present in foods. To examine this problen further it will be necessary to study other foods intrinsically labelled with stable isotopes of Se and the possible interactions of selenite with food constituents. In addition, the forms of the element in foods should be better characterized. The comparative metabolism in humans of the different forms of food Se deserves more extensive exploration.

This work was supported in part by NIH Grant nos. R01-CA-27917 and RR88 and grant-in-aid from the National Live Stock and Meat Board and Ralston Purina Company, St Louis.

\section{REFERENCES}

Björn-Rasmussen, E., Hallberg, L., Isaksson, B. \& Arvidsson, B. (1974). Journal of Clinical Investigation 53, 247-255.

Butler, G. W. \& Peterson, P. J. (1962). New Zealand Journal of Agricultural Research 4, 484-491.

Combs, G. F. \& Pesti, G. M. (1976). Journal of Nutrition 106, 958-966.

Cook, J. D. (1977). Federation Proceedings 36, 2028-2032.

Cousins, F. B. \& Cairney, I. M. (1961). Australian Journal of Agricultural Research 12, 927-943.

Evans, G. W. \& Johnson, A. E. (1977). American Journal of Clinical Nutrition 30, 873-878.

Ganther, H. E. (1968). Biochemistry 7, 2898-2905.

Goddard, D. R. \& Michaelis, L. (1934). Journal of Biological Chemistry 106(2) 605-614.

Griffiths, N. M., Stewart, R. D. H. \& Robinson, M. F. (1976). British Journal of Nutrition 35, 372-382.

Hallberg, L. (1981). Annual Review of Nutrition 1, 123-147.

Heinrich, H. C., Gabbe, E. E., Bartels, H., Oppitz, K. H., Bender-Gotze, C. \& Pfau, A. A. (1977). Klinische Wochenschrift 55, 595-601.

Janghorbani, M., Christensen, M. J., Nahapetian, A. \& Young, V. R. (1982a). American Journal of Clinical Nutrition 35, 647-654.

Janghorbani, M., Christensen, M. J., Steinke, F. H. \& Young, V. R. (1981 a). Journal of Nutrition 111, $817-822$.

Janghorbani, M., Istfan, N. W., Pagounes, J. O., Steinke, F. H. \& Young, V. R. (1982 b). American Journal of Clinical Nutrition 36, 537-545.

Janghorbani, M., Sundaresan, A. \& Young, V. R. (1981 b). Clinica Chimica Acta 113, 267-280.

Janghorbani, M., Ting, B. T. G. \& Young, V. R. (1980). Journal of Nutrition 110, 2190-2197.

Janghorbani, M., Ting, B. T. G. \& Young, V. R. (1981 c). American Journal of Clinical Nutrition 34, $2816-2830$.

Layrisse, M., Martinez-Torres, C., Renzi, M. \& Leets, I. (1975). Blood 45, 689-698.

Lutwak, L. (1969). American Journal of Clinical Nutrition 22, 771-785.

Robinson, M. F., Rea, H. M., Friend, G. M., Stewart, R. D. H., Snow, P. C. \& Thomson, C. D. (1978). British Journal of Nutrition 39, 589-600.

Rudall, K. M. (1952). In Advances in Protein Chemistry, vol. 7, pp. 253-290 [M. K. Anson, K. Bailey and J. T. Edsall, editors]. New York: Academic Press.

Sandström, B. \& Cedarblad, A. (1980). American Journal of Clinical Nutrition 33, 1778-1783. 
Snedecor, G. W. \& Cochran, W. G. (1967). Statistical Methods, 6th ed., pp. 91-109. Ames Iowa: Iowa State University Press.

Solomoms, N. W., Janghorbani, M., Ting, B. T. G., Steinke, F. H., Christensen, M. J., Bijlani, R., Istfan, N. \& Young, V. R. (1982). Journal of Nutrition 112, 1809-1821.

Stewart, R. D. H., Griffiths, N. M., Thomson, C. D. \& Robinson, M. F. (1978). British Journal of Nutrition 40, $45-54$.

Suderman, D. R. \& Cunningham, F. E. (1980). Poultry Science 59, 2247-2249.

Thomson, C. E. \& Stewart, R. D. H. (1974). British Journal of Nutrition 32, 47-57.

Young, V. R., Hussein, M. A., Murray, E. \& Scrimshaw, N. S. (1971). Journal of Nutrition 101, 45-60. 